\title{
CHEMOLYSIS OF A URIC ACID STONE IN A HORSESHOE KIDNEY
}

Malathy Balakrishnan, YC Phan, Jonathan Cobley, and Wasim Mahmalji

Department of Urology, Hereford County Hospital, Hereford, Herefordshire, UK

Corresponding author YC Phan: yihchyn@hotmail.com

Submitted: June 10, 2018. Accepted: June 12, 2018. Published: July 12, 2018.

\section{CASE REPORT}

Chemolysis of kidney stone is not unheard of. However, to our knowledge, there is no previous report of chemolysis of a kidney stone in a horseshoe kidney. We report the first ever case of chemolysis of a stone in a horseshoe kidney. As part of his visible hematuria workup 4 years ago, a 66-year-old gentleman with a history of gout was found to have a horseshoe kidney. In early 2017 , he was seen in the urology clinic with some non-specific abdominal pain without a recent history of visible hematuria, lower urinary tract symptoms, and urinary tract infections. His CT KUB (computed tomography of kidneys, ureters and bladder) revealed a 1.3-cm stone in his horseshoe kidney (Figure 1 and 2). At the same time, his CT KUB has also picked up some retroperitoneal lymphadenopathy in the abdomen and pelvis which were suspicious of lymphoma. His serum uric acid level was noted to be normal. Subsequently, he underwent a laparoscopic right iliac lymph node biopsy which confirmed nodal marginal zone non-Hodgkin's B-cell lymphoma. He was reviewed by the hematology team and they decided to adopt a watch and wait approach to his disease with quarterly CT CAP (computed tomography of chest, abdomen and pelvis) scans. During this period of time, he had several gout attacks and he was started on allopurinol i.e. $100 \mathrm{mg}$ once a day. He also considerably increased his daily fluid intake. 6 months after his initial CT $\mathrm{KUB}$, he was found to be completely stone free on his CT scan (Figure 3 and 4).
FIG. 1 Coronal view of the patient's initial CT scan, demonstrating a $1.3-\mathrm{cm}$ stone in his horseshoe kidney.

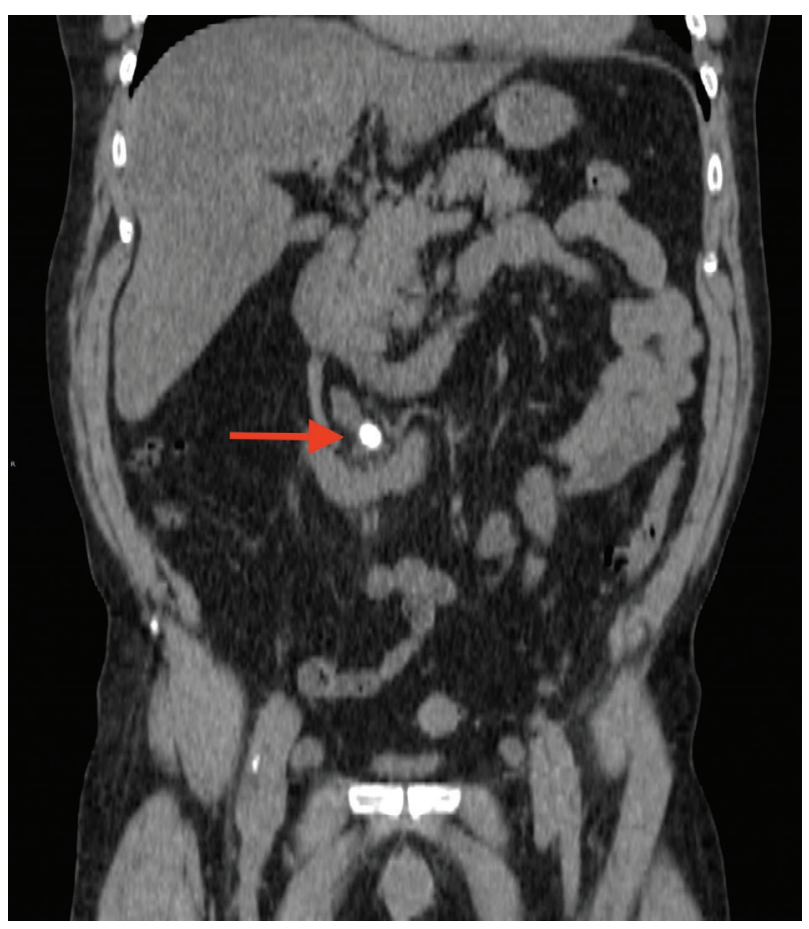

\section{DISCUSSION}

Horseshoe kidney is the most common renal fusion anomaly. ${ }^{1}$ The incidence of horseshoe kidney is estimated to be $1 / 400^{2}$ and it is about twice as common in males than females. ${ }^{3,4}$ Horseshoe kidney may occur 
FIG. 2 Axial view of the patient's initial CT scan, demonstrating a $1.3-\mathrm{cm}$ stone in his horseshoe kidney.

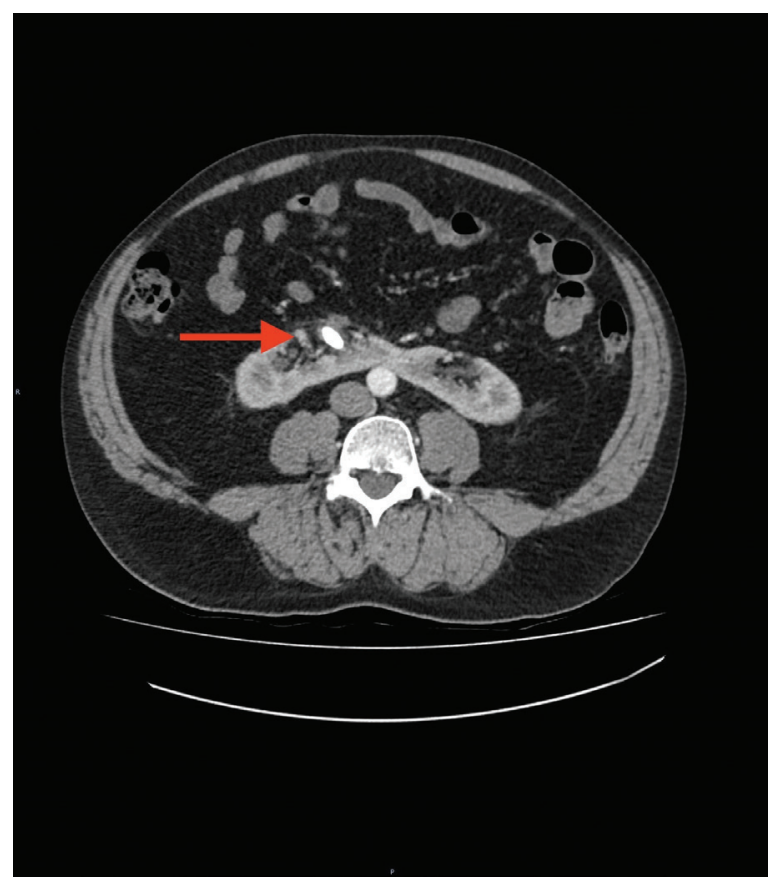

FIG. 4 Axial view of the patient's subsequent CT scan.

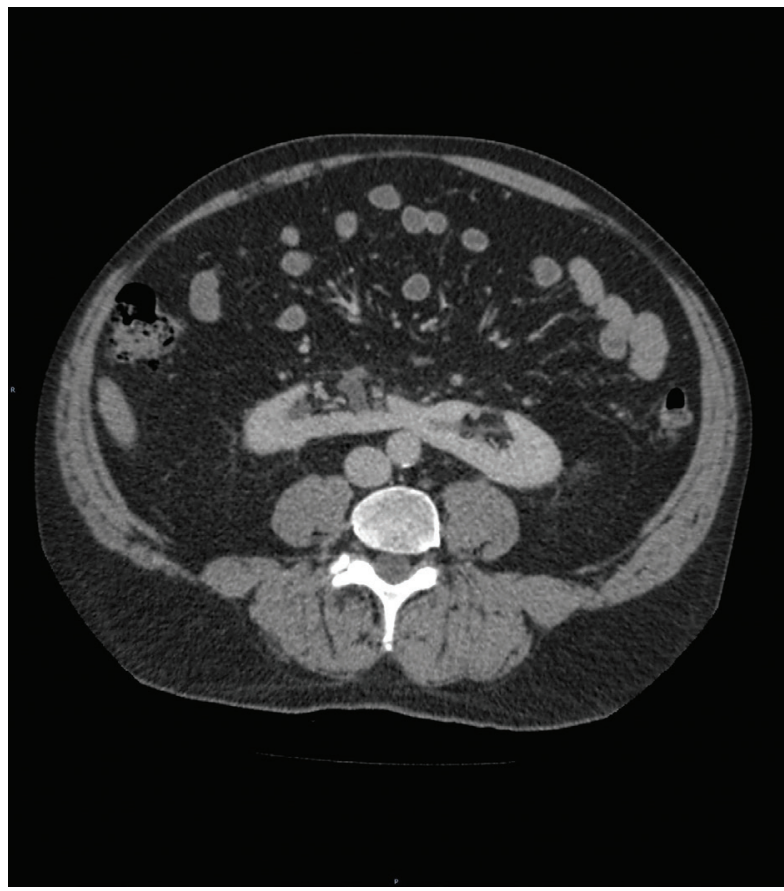

FIG. 3 Coronal view of the patient's subsequent CT scan.

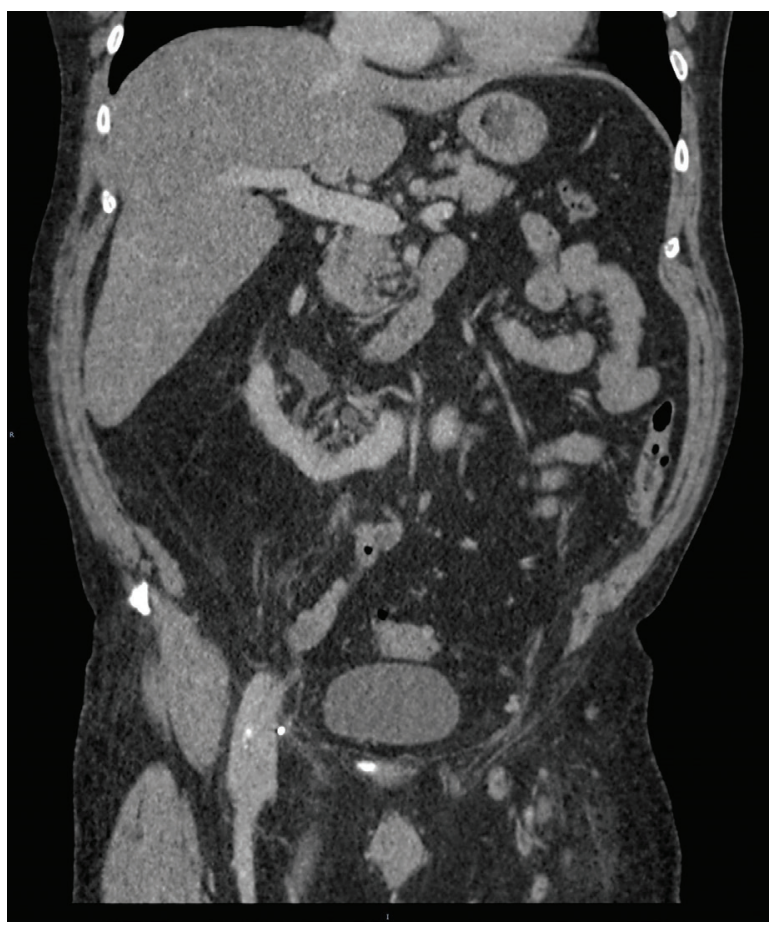

as an isolated entity, but it may also be associated with other congenital anomalies. ${ }^{5}$ More often than not, horseshoe kidneys are found incidentally as they are often asymptomatic. ${ }^{6}$

There are two theories on why horseshoe kidneys are formed. ${ }^{7}$ The theory of mechanical fusion suggests that during the early stage of embryogenesis, the metanephric blastema of the two kidneys come in contact for a longer period than usual due to abnormal flexion or growth of fetal spine and pelvic organs in the fetal pelvis. In the absence of a renal capsule in fetal kidneys, this allows the metanephric blastema to fuse at the point of contact, forming the fibrous isthmus. The other theory suggests a teratogenic event whereby there is an abnormal migration of posterior nephrogenic cells in the fetal kidneys, resulting in the formation of parenchymal isthmus. The presence of isthmus prevents the kidneys from ascending cranially, often arresting at the inferior mesenteric artery.

Due to the nature of the anatomy, drainage of urine from the kidney to the bladder is usually less than ideal. Furthermore, Raj et al. have also found that horseshoe

J Endolum Endourol Vol 1(1):e37-e40; July 12, 2018.

This article is distributed under the terms of the Creative Commons AttributionNon Commercial 4.0 International License. Copyright (c) 2018 Balakrishnan et al. 
kidney patients have hypovolaemia, hypercalciuria and hypocitraturia as common metabolic defects. ${ }^{8}$ These factors explained why patients with horseshoe kidneys have a higher tendency to form kidney stones. A recent meta-analysis performed by Pawar et al. demonstrated that the incidence of stones in a horseshoe kidney is $36 \% .{ }^{9}$ Furthermore, kidney stones are more prevalent in males with horseshoe kidney with calcium-based stones being the most common types of kidney stones. Besides kidney stones, it is also reported that having a horseshoe kidney increases the risk of renal cancer by at least three-fold. ${ }^{10}$ This is attributed to poor urinary drainage and recurrent infections. ${ }^{11}$

Not surprisingly, given the nature of its anatomy, treating stones surgically in a horseshoe kidney can be challenging. However, with modern technology, treatments to these stones are plausible. Symons et al. managed to achieve good stone clearance and good patient outcomes in patients with horseshoe kidneys in their centre using extracorporeal shockwave lithotripsy, flexible ureteroscopy, and laparoscopic pyelolithotomy. $^{12}$

Globally the prevalence of uric acid stones varies geographically, ranging from $3.37 \%$ in Pakistan to $0.17 \%$ in Japan, and from $0.56 \%$ in Spain to $1.12 \%$ in Australia. ${ }^{13}$ Risks factors include age, gender, ethnicity, warm environment, medical conditions such as gout, obesity, hypertension, type 2 diabetes, and myeloproliferative diseases. ${ }^{14,15}$ It is reported that development of uric acid stones is doubled in patients above the age of 65 than in younger patients. ${ }^{16}$

Uric acid accounts for roughly about $10 \%$ of all renal stones. ${ }^{17}$ In a large-scale analysis of 224085 renal stones in Germany, uric acid stones account for $11.7 \%$ in males and $7.0 \%$ in females. ${ }^{18}$ Idiopathic uric acid nephrolithiasis or gouty diathesis is a term used in patients who have no other specific cause for any congenital or acquired causes for metabolic conditions that predispose to the formation of uric acid stones. The three main determinants of uric acid stone formation are low urinary $\mathrm{pH}$, low urine volume, and hyperuricosuria. ${ }^{15,19}$ Of these three determinants, urinary $\mathrm{pH}$ is the most important factor and often this group of patients has persistent low urinary $\mathrm{pH}$.

Chemolysis of uric acid stones is not unheard of with the use of allopurinol, sodium bicarbonate, and alkaline citrate. ${ }^{20-23}$ In fact, it is a recommended treatment for uric acid stones in the EAU (European Association of Urology) urolithiasis guidelines. ${ }^{24}$ Essentially, chemolysis of uric acid stones works by increasing urinary $\mathrm{pH}$ as described by Rodman et al. and Becker. ${ }^{25,26}$ As the $\mathrm{pH}$ rises, the solubility of uric acid increases i.e. the solubility of urine acid increases from less than $1 \mathrm{mmol} / \mathrm{L}$ at $\mathrm{pH} 5$ to nearly $12 \mathrm{mmol} / \mathrm{L}$ at $\mathrm{pH} \mathrm{7}$, causing dissolution of uric acid stone. ${ }^{26}$ Hydration is also important in promoting dissolution of uric acid stone. Needless to say, low volume of urine results in higher concentration of uric acid in the urine. Rodman et al. recommended patients should aim to pass at least 2.5 litre of urine per day. ${ }^{25}$

On the whole, medical dissolution therapy may be considered as the initial management in uric acid stone patients unless there are features such as significant obstruction, infection or severe pain. In the case of our patient, the combination of increased fluid intake and the usage of allopurinol accounts for the chemolysis of his uric acid stone. In conclusion, our case report shows that chemolysis of a uric acid stone is plausible in a patient who has a horseshoe kidney.

\section{REFERENCES}

1. Bauer SB, Perlmutter AD, Retik AB. Anomalies of the upper urinary tract. In: Walsh PC, Retik AB, Vaughan ED Jr, Wein AJ (eds). Campbell's Urology, Vol. 2, 6th edn. Philadelphia, PA: Saunders; 1992.

2. Bauer SB, Perlmutter AD, Retik AB. Anomalies of the upper urinary tract. In: Walsh PC, Retik AB, Vaughan ED Jr, Wein AJ (eds). Campbell's Urology, Vol. 2, 6th edn. Philadelphia, PA: Saunders; 1992.

3. Basar H, Basar R, Basar MM and Erbil M. The comparison of the incidence of horseshoe kidney in autopsy cases versus urologic patient population. Okajimas Folia Anat Jpn 1999;76:137-40.

4. Weizer AZ, Silverstein AD, Auge BK, et al. Determining the incidence of horseshoe kidney from radiographic data at a single institution. J Urol 2003;170(5):1722-6.

5. Nino-Murcia M, DeVries PA, Friedland GW. Congenital anomalies of the kidneys. Clin Uroradiol 2000;1:690-63.

6. Kölln CP, Boatman DL, Schmidt JD, Flocks RH. Horseshoe kidney: a review of 105 patients. J Urol 1972;107(2):203-4.

7. Domenech-Mateu JM, Gonzalez-Compta X. Horseshoe kidney: a new theory on its embryogenesis based 
on the study of a 16-mm human embryo. Anat Rec 1988;222:408-17.

8. Raj GV, Auge BK, Assimos D, Preminger GM. Metabolic abnormalities associated with renal calculi in patients with horseshoe kidneys. J Endourol 2004;18(2):157-61.

9. Pawar AS, Thongprayoon C, Cheungpasitporn W, Sakhuja A, Mao MA, Erickson SB. Incidence and characteristics of kidney stones in patients with horseshoe kidney: A systematic review and meta-analysis. Urology Annals 2018;10(1):87-93.

10. Blackard CE, Melliger GT. Cancer in a horseshoe kidney. Arch Surg 1968;97:616-27.

11. Buntley MD. Malignancy associated with horseshoe: kidney. Urology 1976;8:146-48.

12. Symons SJ, Ramachandran A, Kurien A, Baiysha R, Desai MR. Urolithiasis in the horseshoe kidney: a singlecentre experience. BJU Int 2008 Dec;102(11):1676-80.

13. Trinchieri A, Montanari E. Prevalence of renal uric acid stones in the adult. Urolithiasis 2017;45(6):553-62.

14. Sakhaee K. Epidemiology and clinical pathophysiology of uric acid kidney stones. J Nephrol 2014;27(3):241-45.

15. Maalouf NM. Metabolic syndrome and the genesis of uric acid stones. J Renal Nutrit. 2011;21(1):128-31.

16. Gentle DL, Stoller ML, Bruce JE, Leslie SW. Geriatric urolithiasis. J Urol 1997;158(6):2221-4.
17. Gutman AB, Yü TF. Uric acid nephrolithiasis. Am J Med 1968; 45(5):756-79.

18. Knoll T, Schubert AB, Fahlenkamp D, Leusmann DB, Wendt-Nordahl G, Schubert G. Urolithiasis through the ages: data on more than 200,000 urinary stone analyses. J Urol 2011;185(4):1304-11.

19. Asplin JR. Uric acid stones. Semin Nephrol 1996;16:412-24.

20. Neto M, Pilloff B, Simon J. Dissolution of renal uric acid calculus with allopurinal and alkalization of urine: a case report. J Urol 1976;115(6):740-1.

21. Harbaugh JT. Dissolution of renal calculus with allopurinol: a case report. J Urol 1968;100:412.

22. Godfrey RG, Rankin TJ. Uric acid renal lithiasis: management by allopurinol. J Urol 1969;101:643.

23. Alexander S, Brendler H. Treatment of uric acid urolithiasis with allopurinol: a xanthine oxidase inhibitor. J Urol 1967;97:340.

24. Türk C, Neisius A, Petrik A, et al. Urolithiasis Guidelines [Internet]. European Association of Urology; 2018. Available at: http://uroweb.org/ guideline/urolithiasis/

25. Rodman JS, Williams JJ, Peterson CM. Dissolution of uric acid calculi. J Urol 1984;131(6):1039-44.

26. Becker G. The CARI guidelines. Kidney stones: uric acid stones. Nephrology 2007;12 Suppl 1:S21-S5. 